\title{
RESEÑA DE MI GUERRA EN ESPAÑA DE MIKA
}

\section{ETCHEBÉHÈRE}

REVIEW OF MY WAR IN SPAIN BY MIKA ETCHEBÉHÈRE

Yanira Hermida Martín

Universitat de València 


\section{MIKA ETCHEBÉHÈRE}

\section{Mi guerra de España}

Oviedo: Cambalache, 2019. 2ª edición.

507 páginas.

Cambalache ha actualizado la traducción al castellano (el texto original fue redactado en francés en 1976 y traducido al castellano por la propia autora) de la célebre autobiografía de Mika Etchebéhère publicada en 2003 por Alikornio ediciones.

En esta nueva edición incorporan una parte introductoria titulada: Mi nombre en la historia, a través de la cual nos presentan la figura de Mika Etchebéhère poniéndola en contexto con los procesos históricos en los que su vida y su texto se relacionan, poniéndo énfasis en destacar el papel del feminismo obrero en la España republicana, la configuración del arquetipo de mujer miliciana en los primeros momentos de la Guerra Civil, las dinámicas patriarcales que afrontaron las mujeres combatientes en los frentes de guerra y la vuelta forzada al espacio doméstico que se impuso con el triunfo del fascismo y la imposición de la dictadura franquista. A esta parte le sigue un primer bloque de notas biográficas que nos permiten disponer de una breve pincelada incial del recorrido vivencial de la autora y protagonista de esta obra.

Tras la version íntegra del texto de Mika Etchebéhère, encontramos la segunda parte de las notas biográficas que nos permiten seguir la pista más allá del final de su relato fechado en febrero de 1937 hasta su muerte en París el 7 de julio de 1972. La edición de Cambalache incorpora como cierre del libro una carta fechada el 21 de junio de 1974 en la que Julio Cortázar le agradece el haberle permitido leer el manuscrito de sus memorias, una cuidada bibliografía sobre la época y la figura de Mika, terminando con cuatro mapas que reproducen en el siguiente orden los escenarios de los enfrentamientos en el frente que encabezó la capitana Mika Etchebéhère: Frente de Atienza-Sigüenza de julio a cotubre de 1936, el mapa de la ciudad de Sigüenza en esa época, Frente de Madrid de noviembre de 1936 a febrero de 1937 y como colofón un mapa a detalle del frente de Moncloa Ciudad Universitaria en noviembre de 1936.

A pesar de que el libro apareció publicado en España el mismo año, 1976, en que la autora lo publicó en Francia y lo tradujo al castellano. Esta nueva reedición de la autobiografía de Mika Etchebéhère nos permite comprobar la vigencia del mismo y la necesidad presente que temenos de leer el texto de Mika para recuperar esa parte de conocmimiento y saberes negados por el fascismo durante los 40 años de dictadura y tras el proceso denominado Transición a la democracia su posterior olvido.

La propuesta de Cambalache nos permite acercarnos al texto de Mika Etchebéhère desde una mirada feminista, enfatizando aún más si cabe el gran valor de esta obra. Mi Guerra de España no es un libro más sobre la Guerra Civil, es un testimonio narrado desde los recuerdos 
y vivencias de una mujer que ya fue excepcional en su época y logró derrocar con su ejemplo y su compromise de vida las limitaciones que el patriarcado le había impuesto ya por el simple hecho de nacer como mujer en el seno de una familia migrante, nacida como Mika Feldman ya que procedía de una familia judía afincada en Argentina al escapar de los progroms en Rusia.Tomó el apellido con el que pasó a la historia y por el que será conocida de su union con Hipólito Etchebéhère (Hippo), el que fuera su compañero de vida hasta la muerte del mismo en los comienzos de la Guerra Civil Española.

El libro nos ofrece una mirada femenina a la Revolución Social y sobre todo a la guerra desde el interior, desde las trincheras y las batallas, cuestión que lo convierte en un texto aún más interesante por su carácter excepcional.

Uno de sus muchos méritos es de ser la única mujer extranjera que alcanzó el rango de Capitana en el ejército republicano. Tras el fallecimiento de Hippo, su compañero, encabezó la milicia del POUM en la que ambos se habían alistado cuando dejaron Francia para luchar por la libertad y una Sociedad mejor en aquella España amenzada por el fascismo.

Su columna de milicianos y miliacianas se batirá en la defensa primero de Sigüenza y después de Madrid, en Moncloa, Pineda de Húmera, resistiendo catorce horas los ataques fascistas y en Cerro del Águila.

Su narración nos posibilita enfrentar debates feministas sobre los roles sociales y las desiciones vitales de las mujeres, como comprobar la importancia que le concede a la intendencia y al cuidado de los y las milicainas de su columna y el éxito que tiene en su gestion de las necesidades vitales en plena contienda bélica. Un ejemplo son las menciones a los sacrificios que conlleva sus ideas socio-políticas, por un lado en su negación a poner a sus compañeros en riesgos para recuperar el cadavér de su marido a pesar de su dolor y desolamiento (ETCHEBÉHÈRE, 2019: 64) o cuando explica su desición de no ser madre para dares por entero a la revolución (ETCHEBÉHÈRE, 2019: 440)En la página 115 relata como una de sus compañeras de milicia a la que llaman la Chata le agradece su compromiso revolucionario: "-Todos te damos las gracias por haber venido a luchar por nuestra revolución"( ETCHEBÉHÈRE, 2019: 115). O la íntima cuestión de su vida sexual y su negación al disfrute de la misma para no desequilibrar el funcionamiento de su columna al sentirse estrechamente vigilada en este aspect por sus compañeros y los hombres a su cargo.

¿Qué soy para ellos? Probablemente ni mujer ni hombre, un ser híbrido de una especie particular a quién obedecen ahora sin esfuerzo, que vivía al comienzo a la sombra de su marido, que lo ha remplazado en circunstancias dramáticas, que no ha flanqueado, que siempre los ha sostenido y, colmo de los méritos, ha venido del extranjero a combatir en su guerra.

¿Tengo yo derecho a tomar un amante entre ellos, incluso fuera de ellos, y dejar de pertenecerles? (ETCHEBÉHÈRE, 2019: 251). 
Vemos en el anterior párrafo a modo de ejemplo la potencia del relato de esta lúcida mujer que dejó plasmada en su autobiografía, ofreciendo una reflexión profunda sobre la existencia de las mujeres que participan y protagonizan un proceso revolucionario sin dejar de ser consientes de las opresiones patriarcales que se mantienen y se reproducen en todos los ambientes de la Sociedad. Es por esta, entre otras razones, que su obra merece ser leída y analizada desde la actualidad para comprender las complejas experiencias de luchas y resietencias que gestaron las mujeres de nuestro pasado. 